\title{
IMPLEMENTATION OF ENVIRONMENTAL MANAGEMENT SYSTEM (EMS) IN CONSTRUCTION INDUSTRY: INVESTIGATION OF SUCCESS FACTORS
}

\author{
Siti Maharah Abdul Khalim ${ }^{1, *}$, Chia Kuang Lee ${ }^{1}$ \\ ${ }^{1}$ Faculty of Industrial Management, Universiti Malaysia Gambang
}

ABSTRACT - The number of construction activities nowadays increased rapidly due to urbanization and economic growth. The increased number of construction activities will cause adverse effects and huge impacts on the natural environment, and integrity of the construction process. Compared to the other industries, it is far behind in the implementation of the Environmental Management System (EMS). This paper aims to investigate the success factors of the implementation of EMS in the construction industry. EMS introduced several control strategies with proper management to address environmental issues caused by construction activities. This study reviewed some of the past studies related to EMS, construction industry, and also sustainable development in construction projects. EMS helps in minimizing environmental impacts by providing a framework that supports a construction company through reliable control. EMS integrates environment management into the company's long term planning, daily operations and other quality management system.

ARTICLE HISTORY

Received: 13-8-2020

Accepted: $30-10-2020$

KEYWORDS

Environmental Management

System (EMS)

ISO 14001

Integrity in construction

Success factors

Construction industry

\section{INTRODUCTION}

In Malaysia, the construction industry consists of two areas, such as special trade works and general works. General construction works consist of residential construction, non-residential construction and civil engineering construction. Meanwhile, special trade works include sewerage, electrical works, metal works, plumbing, air conditioning, sanitary works, carpentry, tiling and flooring works and also painting works. Construction projects cover a lot of workloads as the construction industry is considered as one of the huge industry in Malaysia. Construction activities, however, adversely affect the environment (Farouq et al., 2017). Construction projects produce huge challenges in society when the company need to minimize and eradicate the environmental impact and maintain integrity in the construction process. In the construction industry, the working practices developed by the contractors mostly values more on short term profits compared to the long term benefits such as environmental management.

Construction company need to implement an Environmental Management System (EMS) in order to help them manage and improve their environmental performance. Besides that, the construction company can use EMS as a tool used to manage the environmental impacts caused by construction activities, and it provides a meticulous approach and plans measurement for environment protections (Fortunski, 2008). EMS provides the requirements for an organization to manage their company in order to achieve environmental, social and economic goals. In another way, EMS helps in providing a proper framework that supports an organization to achieve environmental goals through appropriate control in construction activities (Farouq et al., 2017). According to Zolfagharian, Nourbakhsh, Irizarry, Ressang, and Gheisari, (2012), $67.5 \%$ of natural resources and $21 \%$ ecosystem in Malaysia is affected by construction activities. It shows that it is essential for a construction company to have environment standard and policy to help them reduce environmental impacts, transportation and energy consumption in construction activities. Therefore, EMS is a set of procedures that describe how a construction company manage its environmental impact on natural resources. According to Arimura, Hibiki and Katayama, (2008), the facility needs to implement an environmental policy and create goals to reduce environmental consequences through management review and systematic auditing.

ISO 14001 was introduced to create an EMS standard and ensure that the implementation of EMS follows the ISO 14001 standard (Arimura et al., 2008). According to Mazzi, Toniolo, Mason, Aguiari and Scipioni (2016), ISO 14001 is universal standards that support the maintenance and the implementation of EMS in order to improve environmental performance. The construction company should complete the procedures for EMS certification, once the procedures completed ISO 14001 would indicate environment management following the ISO 14001. The adoption of ISO 14001 helps the organization to explore more on cost-effective approach which lessens their environmental impacts in construction and get better environmental results (Arimura et al., 2008). The main objective of this paper is to identify the success factors influencing the implementation of EMS in the construction project. The gap in the literature is filed by this study by investigating the success factors in the implementation of EMS and proposed a framework. This paper helps to identify which factors are important and give more influence towards the implementation of EMS 


\section{LITERATURE REVIEW}

EMS is a worldwide tool used to improve environmental management aspects and achieve continuous improvement in environmental performance. EMS developed to be applicable to all size and types of organization (De Oliveira Naves, Salgado and Beijo, 2017) and could be adjusted according to different cultural, geographical and social conditions (Cary and Roberts, 2011). A firm needs environmental obligations to identify environmental threats and manage them. EMS designed a process to manage environmental threats and to reduce the environmental risk of an organization (Cary and Roberts, 2011). Furthermore, EMS provide a framework for environmental protection and help the organization to balance between environmental conditions and socio-economic needs (De Oliveira Naves et al., 2017). The pressure to adopt environmental protection forced most construction companies to have undertaken measures to reduce impacts on the environment.

Organizations globally improve their manufacturing and operating process to reduce environmental impacts. These kinds of actions could lead to resource efficiencies, regulatory requirements and green compassions among companies (Valdes-Vasquez and Klotz, 2013). Furthermore, government policy embraces the implementation of EMS in an organization in term of a market-oriented approach to be environmental friendly (Cary and Roberts, 2011). Government policy demands the company to improve its production efficiency at the same time reduce negative environmental externalities and improve natural resource management.

ISO 14001 was introduced to support the implementation of EMS in the organization. ISO 14001 provides organizations with a tool to assess and control environmental impacts caused by their activities, products and services (De Oliveira, Serra, and Salgado, 2010). According to De Oliveira et al., (2010), the standard provides the following environmental principles; labelling and declaration, auditing, performance evaluation, management and life cycle. ISO 14001 specifies the requirement to enable EMS development and implementation of policies and objectives to take into legal requirements (Rino and Salvador, 2017). The difficulties in the implementation of EMS are mainly due to lack of effort by the organization to reduce circumstances and lack of awareness towards the damage. The certification of ISO 14001 brings changes to the organization, and these changes often cause resistance among the employee. Therefore, commitment from all level in implementing EMS, especially top management, is required to ensure the implementation is successful.

ISO 14001 introduced the instruction for implementing EMS in a general manner. According to De Oliveira et al., (2010), there are no specific instructions to formulate, manage and implement the routines, thus the interpretation and adaption of EMS in firm reality is a significant task in the process. ISO 14001 not only assist the company in environmental performance but also improvement in public image, cost reduction and reduction and reduction of pollution (De Oliveira Naves et al., 2017). Besides that, the certification of ISO 14001 results in the increased competitive advantage and financial performance to improve their reputation.

\section{RESEARCH METHOD}

In order to achieve objectives and answer the research questions, a systematic review was carried out to allow identify, evaluate and synthesize the existing knowledge of this topic from the previous study in a systematic and reproducible way (Yin and Fernandez, 2020). The overall systematic review process is operationalized and presented in Figure 1.

In Step 1: Select Data Sources, comprehensive and extensive search from relevant journal and database is required. The data collected from two databases: Web of Science and Scopus. These two databases are widely known and have a high-quality publication from peer-reviewed journals (Yin and Fernandez, 2020). As the number of relevant citations is huge, the appropriate domain of study needs to be identified and selected. Step 2: Perform Preliminary Search involves preliminary search using the search keywords are inserted and entered under Title, Abstract and Keyword into selected journals databases. The preliminary search recommended to identify relevant articles, ensure the validity of the proposed idea, and the articles are enough to conduct the analysis (Mohamed Tawfik et al., 2019). While doing this step, we could identify a systematic review of determinant factors in implementing EMS Step 3: Analysing and Filtering Studies have taken to ensure that the studies are relevant. The articles retrieved from the preliminary step will be filtered, and the qualities will be synthesized. Unrelated, duplicated, unavailable full-texts or abstract only papers are excluded from the finding (Mohamed Tawfik et al., 2019). In order to refrain the researcher from bias, these exclusions were stated in advance. In Step 4: Summarizing The Evidence, the remaining filtered articles will be briefly analyses, and the articles focusing on the topic of interest will be chosen. All articles should be answering the research questions, having clear and sufficient information (Mohamed Tawfik et al., 2019). This paper will discuss research trends in the form of themes, overall time span and overall journal shares. If an overall meta-analysis cannot be done, subgroup meta-analysis may be practicable (Khan, Kunz, Kleijnen and Antes, 2003). Finally, in Step 5: Interpreting the Findings, the data are synthesized and interpreted from the filtered data of studies. All the issues highlighted in every four steps above should be met and the recommendation must be based on the strength and weaknesses of evidence (Khan et al., 2003). 


\section{DISCUSSION AND RESULTS}

This review consists of five steps, including putting the keywords in the search engine, performing the preliminary search, analysing and filtering studies, summarizing the evidence and lastly interpreting the findings- the detailed steps as shown in Figure 1 below:

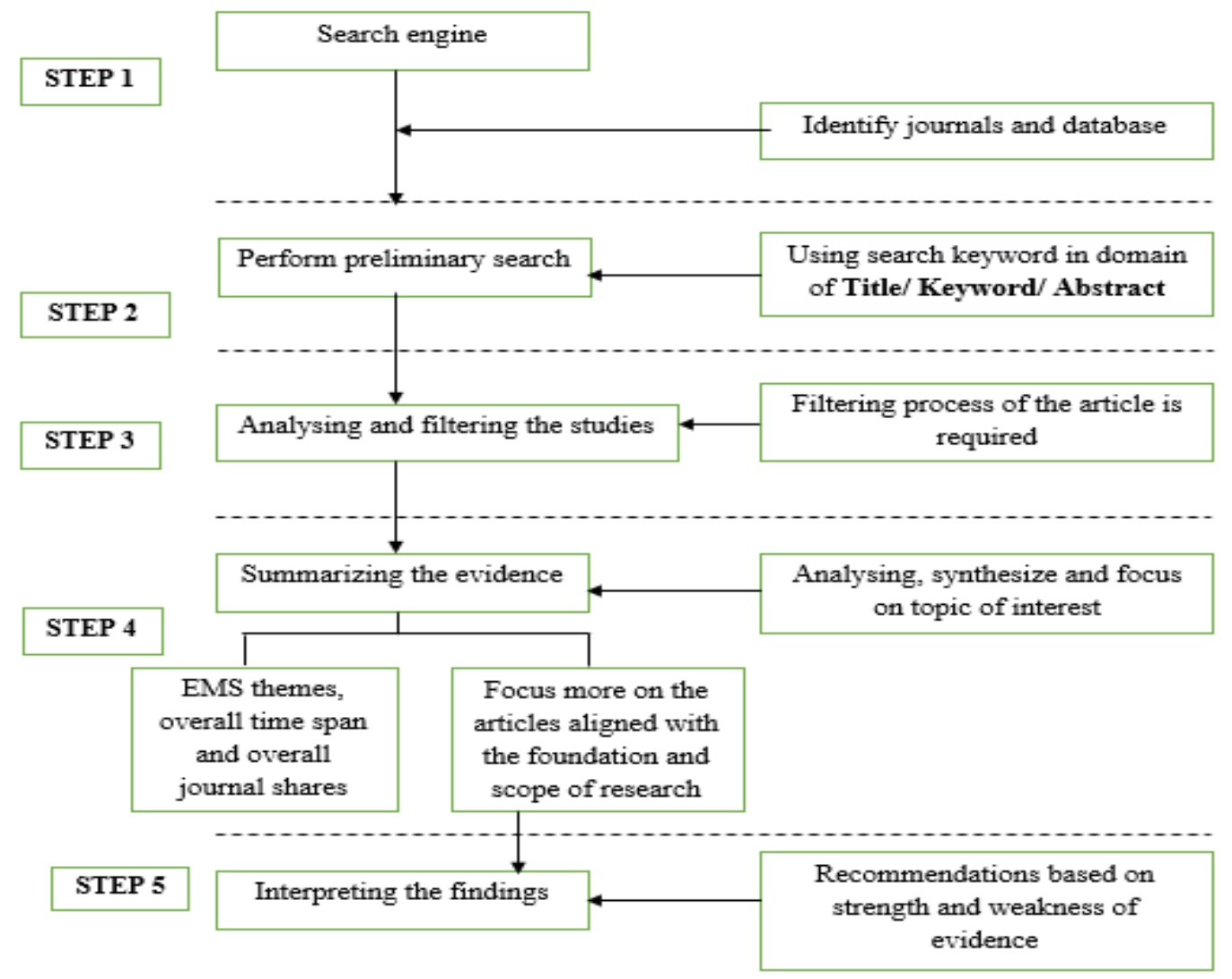

Figure 1: Systematic review steps

\section{Step 1: Select data sources}

The data were selected in the area of expertise of building, sustainability, environmental protection, engineering and construction project management journals where EMS and ISO 14001 are within their scope. Well-known database provider which are Scopus and Web of Science (W.O.S.) were chosen in peer-reviewed of journals, books and conference proceedings. The selection of data in both search engines with the keyword of "Implementation of Environmental Management System", "Environmental Management System", "The Implementation of ISO 14001" and "ISO 14001" was done. The journals that were used for the research of EMS and ISO 14001 included International Journal of Environmental Research and Public Health, Environmental Conservation, Environmental Science and Ecology and etcetera.

\section{Step 2: Perform preliminary search}

In this step, the preliminary search performed by using the keyword mentioned in Step 1, under the configuration of Title/ Abstract/ Keyword" into the selected journals databases. At the beginning of this process, there is no restriction imposed in order to get the earliest published articles. The articles published up to the year 2020 were included. After a preliminary search was done, a total of 907 articles have been retrieved.

\section{Step 3: Analysing and filtering the studies}

The purpose of this step is to assess the quality of studies. All the articles retrieved from Step 2 will be analysed and filtered. The filtering process requires the examination of all 907 articles and the removal of the non-scholarly articles such as introduction, book review, editorial, announcement, the article in press and also discussions and closures. Research under these broad categories was filtered and excluded from the detailed analysis. However, articles from case studies, scholarly papers and forums were maintained in the filtering process. As a result, the number of articles that are related to the implementation of EMS was reduced accordingly as shown in Table 1. 
Table 1: Total articles (before and after the filter)

\begin{tabular}{|c|c|c|}
\hline Journals & Before filter & After filter \\
\hline 1. & Journal of Environmental Management & 169 \\
\hline 2. & Wit Transactions On Ecology And The Environment & 145 \\
\hline 3. & Ecology And Society & 97 \\
\hline 4. & International Journal Of Environmental Research And Public Health & 80 \\
\hline 5. & Water Switzerland & 53 \\
\hline 6. & Environmental Research Letters & 42 \\
\hline 7. & Science Of The Total Environment & 42 \\
\hline 8. & B.M.C. Public Health & 32 \\
\hline 9. & Energies & 31 \\
\hline 10. & ICES Journal Of Marine Science & 30 \\
\hline 11. & Journal Of Cleaner Production & 25 \\
\hline 12. & Journal Of The Air And Waste Management Association & 21 \\
\hline 13. & Environmental Conservation & 19 \\
\hline 14. & Journal Of Applied Ecology & 18 \\
\hline 15. & Sensors Switzerland & 8 \\
\hline 16. & Environmental Science And Technology & 7 \\
\hline 17. & Hydrology And Earth System Sciences & 7 \\
\hline 18. & Water Resources Research & 7 \\
\hline 19. & Sustainability Switzerland & 6 \\
\hline 20. & International Journal Of Life Cycle Assessment & 6 \\
\hline 21. & Journal Of Water And Health & 6 \\
\hline 22. & Agronomy For Sustainable Development & 5 \\
\hline 23. & International Journal Of Health Geographic & 5 \\
\hline 24. & Conservation Biology & 4 \\
\hline 25. & Ecological Applications & 4 \\
\hline 26. & Environmental Modelling And Software & 4 \\
\hline 27. & Global Change Biology & 4 \\
\hline 28. & Integrated Environmental Assessment And Management & 4 \\
\hline 29. & International Journal Of Biodiversity Science Ecosystem Services And Management & 4 \\
\hline 30. & International Journal Of Distributed Sensor Networks & 4 \\
\hline 31. & Land Use Policy & 4 \\
\hline 32. & Polish Journal Of Environmental Studies & 4 \\
\hline 33. & Resources & 4 \\
\hline 34. & Agriculture Ecosystems And Environment & 3 \\
\hline 35. & Asian Social Science & 3 \\
\hline TOTAL & 907 & 239 \\
\hline
\end{tabular}

\section{Step 4: Summarizing the evidence}

Step 4 aims to analyse 239 articles that have been shortlisted. The synthesize will be focusing on the success factors influencing the implementation of Environmental Management System (EMS). In order to achieve this, all 239 articles were analysed and synthesized. These articles were segmented into several themes where deemed appropriate. The selected themes were (1) Sustainable Remediation, (2) Challenges in Implementing EMS, (3) Implementation of EMS, (4) Environmental Performance, (5) Sustainable Practices, (6) Environmental Impact, (7) Challenges in Sustainable Practices, (8) Environmental Protection, (9) Benefits of Environmental Practices, (10) Evaluation and Countermeasures of Environmental / Sustainable Practices, (11) Monitoring Sustainability, (12) Tools for Sustainable Practices and (13) Factors Influencing.

All articles related to EMS were analysed on careful interpretation for each individual article. As shown in Table 2, the theme represents the implementation of EMS and the numbers of articles for each of the theme. The most popular theme is sustainable practices ( 32 articles, 13.4\%), followed by implementation of EMS (26 articles, 10.9\%) and third is the environmental impact (25 articles, 10.5\%). On the other hand, the less favoured theme were challenges in sustainable practices and tools for sustainable practices which both have the same number of articles (11 articles, 4.6\%), benefits of environmental practices (10 articles, $4.3 \%$ ) and lastly monitoring sustainability ( 7 articles, 2.9$)$ become the least theme preferred. 
Table 2: Segmentation of articles according to theme

\begin{tabular}{lll}
\multicolumn{1}{c}{ Theme } & $\begin{array}{c}\text { Number of } \\
\text { Articles }\end{array}$ & Percentage \\
\hline \hline Sustainable remediation & 23 & 9.6 \\
Challenges in implementing EMS & 23 & 9.6 \\
Implementation of EMS & 26 & 10.9 \\
Environmental performance & 24 & 10.0 \\
Sustainable practices & 32 & 13.4 \\
Environmental impact & 25 & 10.5 \\
Challenges in sustainable practices & 11 & 4.6 \\
Environmental protection & 19 & 7.9 \\
Benefits of Environmental practices & 10 & 4.3 \\
Evaluation and countermeasures of environmental / sustainable practices & 13 & 5.4 \\
Monitoring sustainability & 7 & 2.9 \\
Tools for sustainable practices & 11 & 4.6 \\
Factors influencing Implementation of EMS & 15 & 6.3 \\
TOTAL & $\mathbf{2 3 9}$ & $\mathbf{1 0 0}$ \\
\hline
\end{tabular}

\section{Overall journal share}

As shown in Figure 2, the total journal shares of 239 articles were grouped according to their respective journals. Journals of Environmental Management published the most articles (72 articles, 30\%), second International Journal of Environmental Research and Public Health (23 articles, 10\%), and followed by Water Switzerland (20 articles, 8\%). On the other hand, the least journal that published papers related to EMS were Agronomy for Sustainable Development, International Journal Of Health Geographics, Conservation Biology, Environmental Modelling And Software, Integrated Environmental Assessment And Management, International Journal Of Biodiversity Science Ecosystem Services And Management, and International Journal Of Distributed Sensor Networks (1 article, 1\%).

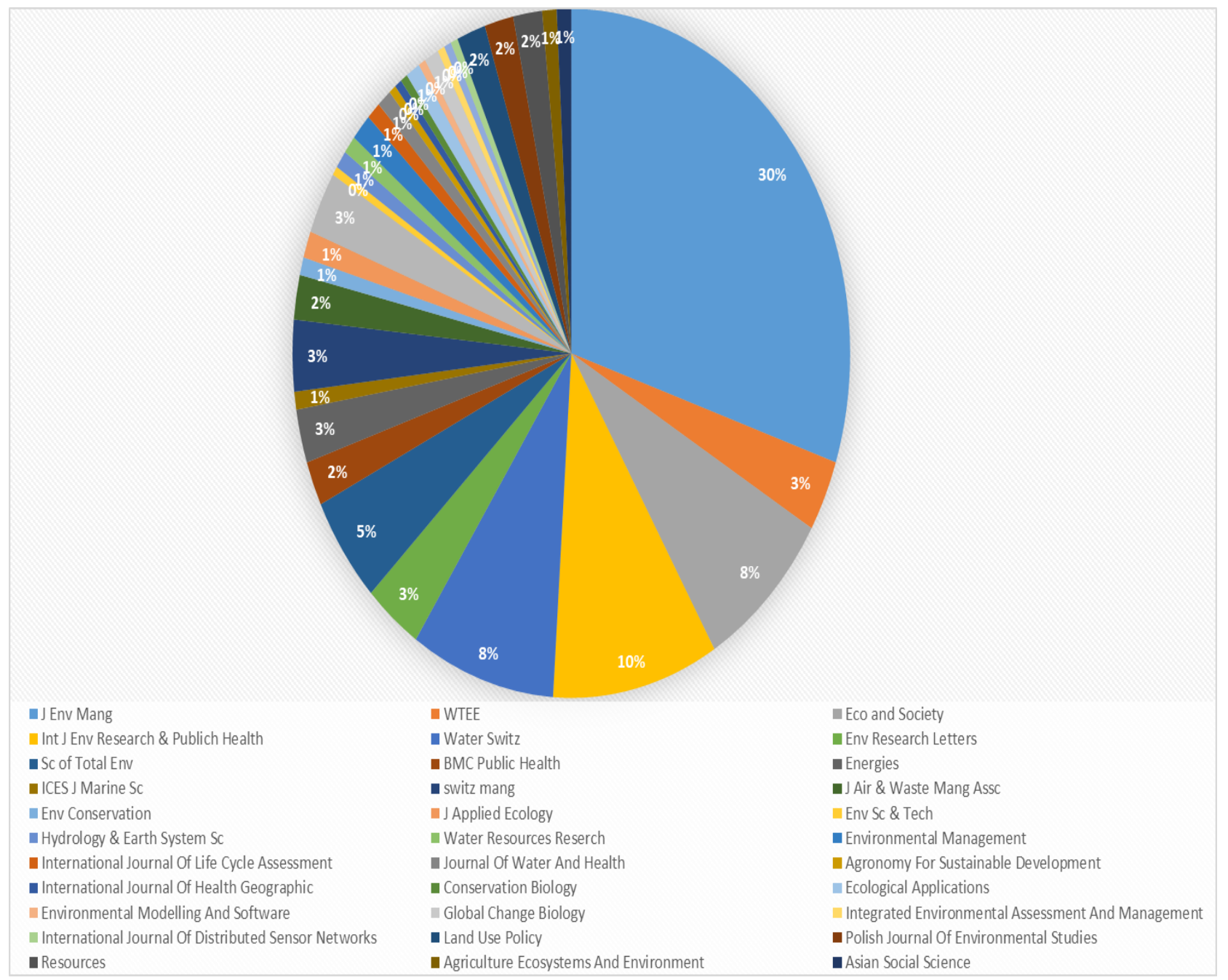

Figure 2: Overall journal shares 


\section{Step 5: Interpreting the findings}

Based on all articles retrieved, the implementation of EMS in a construction project has been increasing, and the standards have been used intensively. Future research directions on the success factors of implementation EMS were recommended based on the evidence of strength and weakness. Four success factors matter in implementing EMS and ISO 1400, which are organizational management approach (1), organizational change (2), technical aspects (3) and external and social bearing (4). For each of the main factors, several sub-factors briefly explained how it is affecting the implementation of EMS in the construction industry.

\section{Management Approach}

For effective implementation of EMS in the organization, top management commitment is necessary for implementing all types of system (Chin, Chiu and Tummala, 1999). The commitment and support, regular management review and relevant environmental policy accepted by all employee include in the management approach (Sambasivan and Fei, 2008). Top management support and leadership are crucial in ensuring wide awareness in organization and understanding of environmental issues for EMS adoption (Zutshi and Sohal, 2004). The consistency of management review, commitment and support, and relevant policy of environmental implementation that can be accepted by employees are some of the approaches that can be taken into considerations by the top management (Sambasivan and Fei, 2008).

There is internal resistance from employees in some organizations when they try to implement new policy and system (De Oliveira Naves et al., 2017). Resistance happens when the employees refuse to give cooperation in implementing a new system in the organization as they already get used to the current system. Employee resistance can be reduced by developing awareness and full understanding of the basic systems (Zutshi and Sohal, 2004a). Top management should be enthusiastic and give full support towards the implementation of EMS to endure such resistance from employees and the organizational change. Not only the top management have big roles in implementing EMS, but each level of the management in the organization has its roles and responsibilities. Everyone in the organization should be mindful about their responsibilities in implementing EMS.

The policy must be actively developed, and it is important that all employees are well informed about the policy to avoid any misunderstanding and misused (Sambasivan and Fei, 2008). The developed policy must be updated and aligned with the implementation of EMS. Top management must review the implementation regularly to ensure that the implementation is effective, sufficient and appropriate (Sambasivan and Fei, 2008). The review can include the complaint or feedback from the customers or third party (Liyin, Hong and Griffith, 2006).

\section{Changes in Organization}

The implementation of EMS may lead to organizational changes, and the top management should ensure that the employees understand and support the changes (Chin et al., 1999). The changes include training and awareness, documentation control, emergency response and preparedness and communication channel (Sambasivan and Fei, 2008).

Both employees and employer should pay extra attention to the changes occurred in their organization before and after the implementation. Employees should be equipped with knowledge and awareness about the effects of environmental operations and actions (Liyin et al., 2006). Education and training are required in order to enhance the proficiencies of employees and help them to adapt to the new system. Training that can be conducted by the company includes target and objectives, policy development of EMS, benefits and advantages, job requirements and the results of non-conformities in the EMS implementation. For improving employees awareness towards environmental issues, educational and training of green issues need to be initiated (Hu and Hsu, 2010).

Keeping an up-to-date and complete all documented system covering procedures and operations is a huge challenge faced by the organization (Zutshi and Sohal, 2004a). The environmental documentation must be updated and communicated across the whole organization as early as possible (Liyin et al., 2006). The documentation must be established and maintained by the organization (Sambasivan and Fei, 2008). An organization should update and review its documentation at least once annually (Zutshi and Sohal, 2004a).

Companies might have to face different problems on-site pertaining to environmental issues as it will affect their performance (Liyin et al., 2006). The organization need to have proper response planning to the emergencies. It is necessary for them to have suitable equipment and facilities to overcome possible environmental issues (Sambasivan and Fei, 2008).

Having a proper communication channel to deliver all kinds of information on EMS is necessary. The communication channel should include all the workers in the organization and make sure they are alert with all the updated information. For easy reference and immediate response of the emergency and accidents situations, the documentation of procedures must be well organized and maintained (Sambasivan and Fei, 2008). It will help the organization to avoid any worst-case scenario when accidents happen during the implementation of EMS 


\section{External and Social Aspects}

External and social aspects are important in the effectiveness of the implementation of EMS Market pressure, employees relations, environmental legislation and customer requirements are included in external and social aspects (Sambasivan and Fei, 2008). Most of developing country such as Malaysia portrays strict environmental legislation to avoid any environmental damage by punishing the offenders (Sayre, 1996; Thornton, 2000). Such enactment pressures the organization to adopt and implement environmental policy to prove evidence to stakeholders and regulators about their competencies (Sayre, 1996; Thornton, 2000).

Most of the construction companies developed an environmental policy to prove their competencies in the market as it demands them to be environmentally friendly. The demand pressures from globalization are intertwined with the management problems and operations management (Lee, 2008). Service and manufacturing sector companies feel the market pressure to implement environmental standards (Sambasivan and Fei, 2008). The competition is fierce and robust among the construction companies, and it became one of the reasons why most of the organization should have an environmental policy.

The implementation of EMS will demand employees to work as a team, and the effectiveness of EMS depends on the employees' involvement (Ann, Zailani and Wahid, 2006). Strong involvement will help them to increase team spirit, stimulate loyalty and productive staffs in a strong team working environment. Their loyalty and spirit as a team will improve employee relations and contribute significantly to the success of EMS implementation (Sambasivan and Fei, 2008).

For controlling the impact on the environment, the governments have implemented different policies and regulations (Liyin et al., 2006). Since the government is the authorized body and policymaker, the new regulations must comply with the standards and requirements (Ismail, Said, Mohd Muzni and Mohd Shafiei, 2015). An effective legal framework needs to be implemented (Ismail et al., 2015).

Most of the construction companies adopting EMS need to be responsive to their customers' pressure (Mavi, GolsefidAlavi, Hessami, Shekaf and Soleimani-Nezhad, 2012). They need to assure that their suppliers conform to the ISO 14001 standards (Mavi et al., 2012). However, this environmental standard is considered to be consistent as the companies integrate and simplify the environmental protection program into their organization framework (Sambasivan and Fei, 2008).

\section{Technical Aspects}

The effectiveness of the implementation of EMS is highly influenced by technical aspects. Technical aspects include assistance from an environmental specialist, production process enhancement and availability of monitoring measuring equipment. Technical aspects also include specialist assistance in environmental, monitoring and measuring equipment and also production process enhancement (Sambasivan and Fei, 2008).

Specialist assistance in environmental issue is needed when the organization is new to the policy, and they require someone expert in handling those issues. Environmental specialist will develop and implement response actions aligned to the environmental legislation (Chin et al., 1999). The limited knowledge and understanding of pollution control, risk assessment and control, and management issues demand the organization to hire a specialist. The specialist will guide them on how to develop response action in their organization, and it will improve their environmental performance (Chavan, 2005). The improvement will lead to acceptance and agreement to environmental legislation.

Reliable equipment is required to continuously monitor and measure all the construction activities to avoid any bad impacts on the environment. All firms certified in E.M.D. Must complete all the implementation process of all metrological requirement in ISO 14001 standard (Beltra`n, Mun uzuri, Rivas and Gonzalez, 2010). The equipment could help the organization to record all the information related to EMS to monitor their performance, implement appropriate operational control and objectives' agreement (Sambasivan and Fei, 2008). Monitoring and controlling of the equipment also help the production process towards becoming environmentally friendly.

Process of production is the indicator that the firm used to ensure that its resources are effective to meet their respective objectives (Padma, Ganesh and Rajendran, 2008). The indicator could be used to control the mechanism to enhance the production process effectively (Sambasivan and Fei, 2008). 


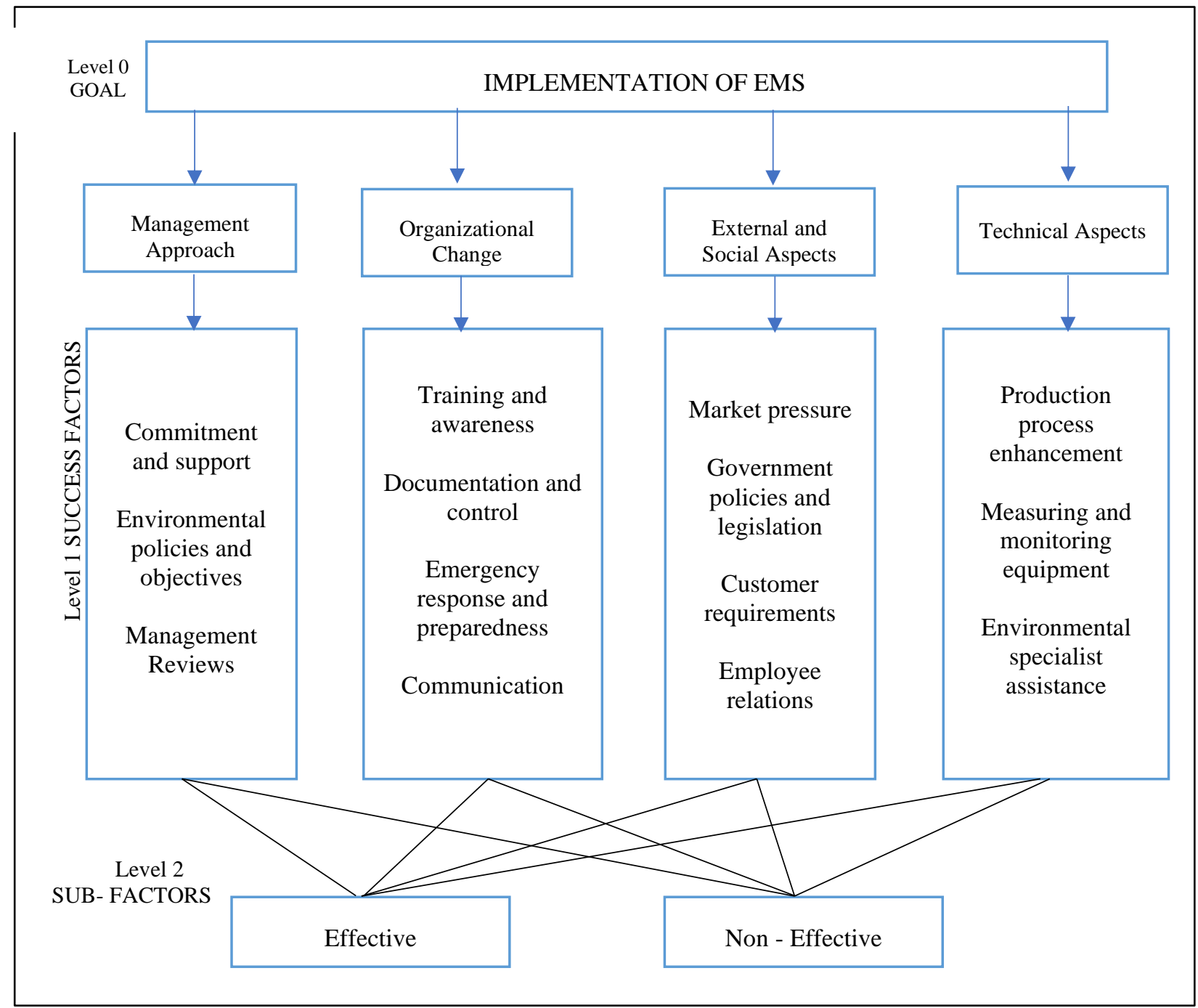

Figure 3: The proposed framework in the implementation of EMS

The proposed success factors, as shown in Figure 3, consist of four stages. The first level is the objective of the framework, implementation of EMS. The first and second level are the success factors in EMS implementation. Meanwhile, the fourth level results to act as a guideline, whether the implementation is effective or vice versa. This framework helps to identify which factors is affecting the implementation of EMS an organization based on the results.

\section{CONCLUSION}

In this paper, a systematic review was used to identify the success factors in implementing EMS in the construction industry. After all the journals have been analysed, the total journal shares of 239 articles were grouped according to their respective journals. Journals of Environmental Management published the most articles (30\%), second International Journal of Environmental Research and Public Health (10\%), and followed by Water Switzerland (8\%). There are four success factors required from the systematic review from previous studies; management approach (1), changes in organization (2), external and social aspects (3) and lastly technical aspects (4). All these factors have their importance in implementing EMS, and they could help the organization to implement EMS successfully. The critical success factors are applicable to all types of firms regardless of their size, sector or ownership. Still, there are several challenges that prevent companies from obtaining their EMS certificates. Several initiatives that could be taken into consideration, for example, the environmental performance after the implementation of EMS could be observed while focusing more on the organization's internal activities and construction integrity towards environmental management activities and conducting more programs related to environmental awareness in the construction industry. 


\section{REFERENCES}

Ann, G. E., Zailani, S., \& Wahid, N. A. (2006). A study on the impact of Environmental Management System (EMS) certification towards firms' performance in Malaysia. Management of Environmental Quality: An International Journal, 17(1), 73-93. https://doi.org/10.1108/14777830610639459

Arimura, T. H., Hibiki, A., \& Katayama, H. (2008). Is a voluntary approach an effective environmental policy instrument? A case for environmental management systEMS Journal of Environmental Economics and Management, 55, $281-295$. https://doi.org/10.1016/j.jeem.2007.09.002

Beltra`n, J., Mun uzuri, J., Rivas, M., \& Gonzalez, C. (2010). Metrological management evaluation based on ISO 10012: An empirical study in ISO 14001 certified Spanish companies. Energy, 35, 140-147.

Cary, J., \& Roberts, A. (2011). The limitations of environmental management systems in Australian agriculture. Journal of Environmental Management, 92, 878-885. https://doi.org/10.1016/j.jenvman.2010.10.055

Chavan, M. (2005). An appraisal of environment management systems: A competitive advantage for small businesses "A" listed. Management of Environmental Quality: An International Journal, 16(5), 444-463. https://doi.org/10.1108/14777830510614321

Chin, K. S., Chiu, S., \& Tummala, V. M. R. (1999). An evaluation of success factors using the A.H.P. to implement ISO 14001-based EMS International Journal of Quality and Reliability Management, 16(4), 341-361.

De Oliveira Naves, F., Salgado, E. G., \& Beijo, L. A. (2017). Analysis of the Environmental Management System based on ISO 14001 on the American continent. Journal of Environmental Management, 199, $251-262$. https://doi.org/10.1016/j.jenvman.2017.05.049

De Oliveira, O. J., Serra, J. R., \& Salgado, M. H. (2010). Does ISO 14001 work in Brazil? Journal of Cleaner Production, 18, 17971806. https://doi.org/10.1016/j.jclepro.2010.08.004

Farouq, M. M., Lawan, U. F., Garba, N., Anwar, F. H., Baba, Z. B., Labbo, M. S., \& Aliyu, D. S. (2017). Implementation of Environmental Management System in Construction Industry : A Review. Journal of Mechanical and Civil Engineering, 14(5), 33-38. https://doi.org/10.9790/1684-1405043338

Fortunski, B. (2008). Does the environmental management standard ISO 14001 stimulat sustainable development? An example from the energy sector in Poland. Management of Environmental Quality, 19(2), $204-212$. https://doi.org/10.1108/14777830810856582

$\mathrm{Hu}$, A. H., \& Hsu, C. W. (2010). Critical factors for implementing green supply chain management practice: An empirical study of electrical and electronics industries in Taiwan. Management Research Review, 33(6), 586-608.

Ismail, R., Said, I., Mohd Muzni, S. S., \& Mohd Shafiei, M. W. (2015). The Implementation of Environmental Management in Malaysian Construction Project. Australian Journal of Basic and Applied Sciences, 9(7), 349-353.

Khan, K. S., Kunz, R., Kleijnen, J., \& Antes, G. (2003). Five steps to conducting a systematic review. Journal of the Royal Society of Medicine, 96, 118-121. https://doi.org/10.1258/jrsm.96.3.118

Lee, C. W. (2008). Green suppliers with Environmental Performance in the supply chain perspective. Journal of Asia Pasific Management Review, 13(4), 731-745.

Liyin, S., Hong, Y., \& Griffith, A. (2006). Improving environmental performance by means of empowerment of contractors. Management of Environmental Quality: An International Journal, 17(3), 242-250.

Mavi, R. K., Golsefid-Alavi, M., Hessami, H. Z., Shekaf, S. M., \& Soleimani-Nezhad, N. (2012). Evaluation and Ranking of Success Factors and Benefits of ISO 14001-Based EMS Implementation Using the TOPSIS Method. Journal of Applied Environmental and Biological Sciences, 2(8), 419-427.

Mazzi, A., Toniolo, S., Mason, M., Aguiari, F., \& Scipioni, A. (2016). What are the benefits and difficulties in adopting an environmental management system? The opinion of Italian organizations. Journal of Cleaner Production, 139, 873-885. https://doi.org/10.1016/j.jclepro.2016.08.053

Mohamed Tawfik, G., Surya Dila, K. A., Mohamed, M. Y. F., Dao, N. H. T., Nguyen, D. K., Ahmed, A. M., \& Nguyen, T. H. (2019). A step by step guide for conducting a systematic review and meta-analysis with simulation data. Tropical Medicine and Health, 47(1), 1-9. https://doi.org/10.1186/s41182-019-0165-6

Padma, P., Ganesh, L. S., \& Rajendran, C. (2008). A study on the ISO 14000 certification and organizational performance of Indian manufacturing firms. Benchmarking: An International Journal, 15(1), 73-100. https://doi.org/10.1108/14635770810854353

Rino, C. A. F., \& Salvador, N. N. B. (2017). ISO 14001 certification process and reduction of environmental penalties in organizations in Sao Paulo State, Brazil. Journal of Cleaner Production, 142, 3627-3633. https://doi.org/10.1016/j.jclepro.2016.10.105

Sambasivan, M., \& Fei, N. Y. (2008). Evaluation of critical success factors of implementation of ISO 14001 using analytic hierarchy process (A.H.P.): a case study from Malaysia. Journal of Cleaner Production, 16, 1424-1433. https://doi.org/10.1016/j.jclepro.2007.08.003

Sayre, D. (1996). Inside ISO 14000: the competitive advantage of environmental management. Delray Beach, FL: St. Lucie Press.

Thornton, R. (2000). ISO 14001 certification mandate reaches automobile industry. Environmental Quality Management, 10(1), 8993.

Valdes-Vasquez, R., \& Klotz, L. E. (2013). Social sustainability considerations during planning and design: Framework of processes for construction projects. Journal of Construction Engineering and Management, 139(1), 80-89. https://doi.org/10.1061/(ASCE)CO.1943-7862.0000566

Yin, J., \& Fernandez, V. (2020). A systematic review on business analytics. Journal of Industrial Engineering and Management, 13(2), 283-295. https://doi.org/10.3926/jiem.3030

Zolfagharian, S., Nourbakhsh, M., Irizarry, J., Ressang, A., \& Gheisari, M. (2012). Environmental impacts assessment on construction sites. Construction Research Congress 2012: Construction Challenges in a Flat World, Proceedings of the 2012 Construction Research Congress, 1750-1759. https://doi.org/10.1061/9780784412329.176

Zutshi, A., \& Sohal, A. (2004a). A study of the environmental management system (EMS) adoption process within Australasian organisations - 2. Role of stakeholders. Technovation, 24, 371-386. https://doi.org/10.1016/S0166-4972(02)00115-3

Zutshi, A., \& Sohal, A. S. (2004b). Adoption and maintenance of environmental management systems: Critical success factors. Management of Environmental Quality: An International Journal, 15(4), 399-419. https://doi.org/10.1108/14777830410540144 


\section{ACKNOWLEDGEMENT}

The authors would like to thank UMP RDU1703296 for the support of this study.

\section{AUTHORS' BIOGRAPHY}

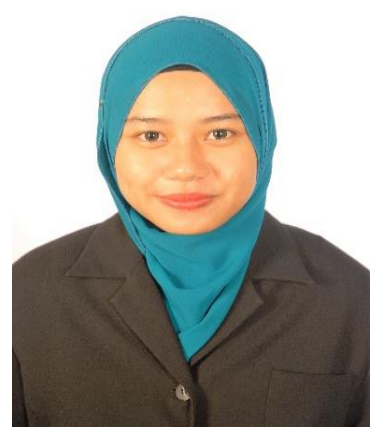

Siti Maharah Abdul Khalim has a Bachelor Degree in Project Management and Master of Science (Project Management) from Universiti Malaysia Pahang. Her master research is focusing more on the Environmental Management System (EMS) in the construction industry. She would like to gain more knowledge and experience in the construction industry as the construction industry is one of the biggest industry in Malaysia.

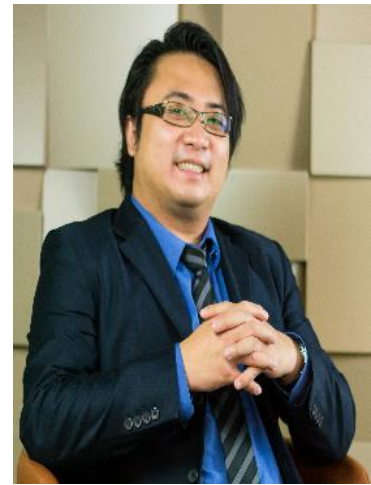

Dr Lee has a Bachelor Degree in Quantity Surveying (B.Q.S) and Master of Science (MSc Construction Contract Management) from Universiti Teknologi Malaysia. He earned a PhD in Civil Engineering from The University of Auckland, New Zealand in 2017, focusing mainly on the field of Construction Alternative Dispute Resolution (A.D.R.) method. He has several professional qualifications and credentials, such as : Certified in Quantitative Risk Management (CQRM) by International Institute of Professional Education \& Research (IIPER) , Project Management Professional (P.M.P.) by Project Management Institute (PMI), Certified as Professional Technologist by the Malaysia Board of Technologists (MBOT), and Train the Trainers (T.T.T.) by HRDF. 